\title{
A LEITURA DE EMOÇÕES NO LIVRO INFANTIL ILUSTRADO: PALAVRAS E IMAGENS
}

\author{
READING EMOTIONS IN CHILDREN'S PICTUREBOOKS: \\ WORDS AND IMAGES
}

\begin{abstract}
Elenice Andersen ${ }^{1}$
RESUMO: Este artigo aborda a dimensão emocional da leitura do livro infantil ilustrado. Tem por objetivo propor, com base em evidências de estudos cognitivos sobre a leitura de narrativas de ficção, um olhar para o livro que valorize a experiência vicária da criança na interação com as emoções das personagens (MIALL, 1989; NIKOLAVEJA, 2013), bem como o papel dessa experienciação no desenvolvimento da empatia (DJIKIC; OATLEY; MIHNEA, 2013). Por meio dos procedimentos metodológicos da Análise de Conteúdo (BARDIN, 1977), orientados pelas categorias de relações entre palavra e imagem, conforme Nikolaveja (2013), discute possibilidades de leitura de emoções em uma obra da literatura infantil nacional destinada ao leitor iniciante, analisando as representações construídas colaborativamente por escritor e ilustrador de como as personagens pensam e sentem. Conclui que a dimensão emocional é onipresente na leitura e, portanto, necessita de uma abordagem que reconheça a indissociabilidade cognição-emoção (DAMÁSIO, 2012 [1994]). Além disso, propõe que as narrativas ficcionais infantis ilustradas, além de contribuir para a alfabetização verbal e visual, oferecem uma fecunda possibilidade de leituras sobre si e sobre o outro, que podem favorecer o desenvolvimento de importantes habilidades socioemocionais na criança, como a empatia.
\end{abstract}

PALAVRAS-CHAVE: Leitura. Emoção. Empatia. Livro Ilustrado. Multimodalidade. Literatura Infantil.

ABSTRACT: This paper discusses the emotional dimension of reading in picturebooks addressed to young readers. It aims to propose, based on evidence from cognitive studies on reading fictional narratives, a look for the picturebook that values the child's vicarious experience in interacting with character emotions (MIALL, 1989; NIKOLAVEJA, 2013), as well as the role of this experience in the development of empathy (DJIKIC; OATLEY; MIHNEA, 2013). Through the methodological procedures of Content Analysis (BARDIN, 1977), guided by the categories of relationships between word and image, according to Nikolaveja (2013), discusses possibilities of reading emotions in a picturebook of Brazilian children's literature aimed at the beginning reader, analyzing the collaboratively constructed representations by writer and illustrator of how characters think and feel. It concludes that the emotional dimension is omnipresent in reading and, therefore, needs an approach that recognizes the inseparability cognition-emotion (DAMÁSIO, 2012 [1994]). In addition, it proposes that illustrated children's fictional narratives, in addition to contributing to verbal and visual literacy, offer a fertile possibility of reading about themselves and others, which may favor the development of important socioemotional skills in children, such as empathy.

KEYWORDS: Reading. Emotion. Empathy. Picturebook. Multimodality. Children's literature.

\section{Introdução}

A pesquisa atual em cognição evidencia como escritores de narrativas ficcionais têm sido hábeis em apreender as emoções humanas, favorecendo que a leitura de suas obras proporcione aos leitores uma maior compreensão de si e do outro. Pelo aspecto factual dessas narrativas, que permitem a crença em mundos imaginados, elas costumam ter por tema típico o eu e suas interações no mundo social (DJIKIC; OATLEY; MIHNEA, 2013).

Ao criar, o ficcionista reporta-se à realidade e, por isso, penetra nos motivos das ações próprias e alheias, construindo situações imaginárias que, às vezes, falam mais do real do que qualquer texto científico (ASSIS BRASIL, 2019). Na ficção, são simulados os objetivos de outras pessoas da mesma maneira que são simulados nossos próprios objetivos (NIKOLAVEJA, 2012), de modo que a boa ficção permite que os leitores se insiram na

\footnotetext{
1 Pós-doutoranda em Escrita Criativa (PUCRS). Professora Associada (UFSC). E-mail: andersen.elenice@gmail.com
} 
mente, objetivos e intenções das personagens, como parte da experiência na leitura (DJIKIC; OATLEY; MIHNEA, 2013).

Em se tratando da leitura de ficção na infância, esse processo também é evidenciado. A compreensão dos estados emocionais das personagens já pode ser observada em crianças de três e quatro anos (MARMOLEJO-RAMOS; HEREDIA, 2006). Conforme pontua Nikolaveja (2013), crianças muito pequenas respondem à dimensão emocional de livros ilustrados, e isso possui implicações pedagógicas, uma vez que a leitura desses livros tem um importante papel no preparo dessas crianças para lidar com a empatia na vida real (NIKOLAVEJA, 2013).

Considerando a importância da leitura de ficção para o desenvolvimento emocional do ser humano, este trabalho tem por objetivo propor um olhar para o livro infantil ilustrado que valorize a experiência vicária da criança na interação com as emoções das personagens, ressaltando o papel dessa experiência no desenvolvimento da empatia. Com isso, proponho outra perspectiva para a abordagem da leitura, que ultrapasse o tratamento focado exclusivamente em estratégias cognitivas de leitura do verbal, e valorize, igualmente, as estratégias de leitura multimodais que se relacionam ao desenvolvimento emocional da criança. Para tanto, na próxima seção, apresento as pesquisas que fundamentam este estudo, começando pela definição de emoções, para, em seguida, discorrer sobre o papel dessas emoções na leitura, especialmente na leitura de livros ilustrados. Após a exposição, analiso uma obra de literatura infantil, discutindo possibilidades de leitura de emoções de personagens, em sua relação com a empatia. Busco, dessa forma, contribuir, com base em estudos na área, para uma formação do leitor mais integral e humana.

\section{Emoções, empatia e leitura de narrativas infantis ilustradas}

De acordo com o neurocientista António Damásio (2012 [1994]), as emoções humanas são corporificadas e desencadeiam uma série de alterações químicas e orgânicas que têm, entre as suas funções, comunicar nossos estados mentais a outras pessoas. Elas podem ser entendidas, em linhas gerais, como a combinação de um processo avaliatório mental com respostas dispositivas a esse processo, que resultam num estado emocional do corpo (DAMÁSIO, 2012 [1994], p. 135). Os seres humanos, assim, estão programados para reagir com uma emoção de modo pré-organizado quando certas características de estímulos são detectadas individualmente ou em conjunto. Por exemplo, no caso do medo, essas características podem ser o tamanho de um animal ou determinados sons. Tais características são processadas e depois detectadas por um componente do sistema límbico do cérebro que ativa um estado do corpo, característico de uma determinada emoção, e que altera o processamento cognitivo de modo a corresponder a esse estado (DAMÁSIO, 2012 [1994], p. 133).

Nesse sentido, algumas dessas representações dispositivas não são inatas; mas são adquiridas sob a influência das inatas. Elas incorporam a experiência pessoal e única para cada indivíduo ao longo da vida. Por essa razão, as emoções humanas podem ser divididas em primárias e secundárias. As emoções primárias consistem em emoções pertencentes a um mecanismo pré-organizado, que resulta em um padrão específico de reação corporal. As secundárias vão sendo construídas em virtude das experiências e são desencadeadas após um processo mental automático de avaliação. O organismo humano está dotado de mecanismos automáticos de sobrevivência ao qual a educação e a aculturação acrescentam um conjunto de estratégias de tomada de decisão socialmente desejáveis, que servem de base à construção de uma pessoa. Os mecanismos neurais requerem, portanto, a intervenção da sociedade para se tornarem aquilo que se tornam, estando relacionados tanto com uma determinada cultura como com a neurobiologia geral. 
Mas qual a relevância desse processo para a pesquisa sobre a leitura de narrativas? Estudos em cognição têm oferecido evidências de que esse processamento emocional também pode ocorrer por meio da experiência vicária, a partir da leitura de ficção. Em um trabalho clássico na área, Miall (1989) observou que o afeto, como a experiência subjetiva de emoções e sentimentos, influencia de tal forma a leitura que pode exercer o papel principal na direção da compreensão de narrativas literárias. De acordo com sua pesquisa, é o afeto que abastece o processo interpretativo com uma variedade de contextos potenciais para atribuir significado aos elementos do texto, a partir das experiências prévias do leitor. Assim, o afeto oferece, antes mesmo da leitura, uma pré-estruturação do significado global da narrativa, e, durante a leitura, conduz os leitores a se identificar com a experiência e com os motivos das personagens, levando-os a compartilhar de seus sentimentos e objetivos.

Djikic, Oatley e Mihnea (2013) explicam que as histórias fictícias são simulações complexas da realidade. Ao lermos, por exemplo, a simulação de uma história em que uma personagem está brava com outra, podemos entender e antecipar o que provavelmente acontecerá, e, se forem adicionados outros fatores, como traços de personalidade, as simulações vão se complexificando. Conforme os pesquisadores, a função dessas simulações ficcionais é permitir-nos imaginar mundos possíveis e possíveis resultados, descobrir o que outras pessoas estão pensando e entender as emoções dos outros, o que promove uma identificação, a partir do uso de processos de simulação interna (DJIKIC, OATLEY, MIHNEA, 2013).

Trabalhos mais recentes, como os de Dávalos e León (2017), também revelam que o leitor assume um papel ativo na leitura, compartilhando emoções e se situando no lugar do protagonista, contribuindo com elementos pessoais na construção de uma coerência global para a narrativa. Isso se explica, segundo os autores, pela habilidade humana de entender o seu semelhante, de aprender com ele e de se identificar com o outro por meio da compreensão de suas intenções e estados mentais.

Considerando-se isso, uma questão que se torna relevante para a pesquisa na área é se o hábito de ler ficção poderia favorecer o desenvolvimento da empatia. Djikic, Oatley e Mihnea (2013) realizaram um experimento sobre o potencial da literatura para aumentar a empatia, verificando se a ficção é capaz de suscitar empatia nos leitores. Eles realizaram um experimento no qual mediram mudanças de empatia em pessoas que foram solicitadas a ler um conto fictício ou um ensaio não-fictício. Os participantes que eram leitores de ficção frequentes obtiveram pontuações mais altas nas medidas de empatia, o que levou os pesquisadores a concluir que há um papel da literatura fictícia na facilitação do desenvolvimento de empatia.

Esse fenômeno pode ser observado desde cedo. Marmolejo-Ramos e Heredia (2006) constataram que a compreensão de estados emocionais das personagens de um texto narrativo pode ser observada precocemente, em crianças de três e quatro anos. Para os pesquisadores, essa descoberta tem implicações tanto clínicas como pedagógicas. Pedagógicas, pela evidente relação com o ensino da compreensão leitora. Mas também implicações clínicas, uma vez que psicólogos podem conseguir, por meio do trabalho com textos, um tipo de modificação das representações internas ligadas à compreensão das emoções, que podem ter efeito no comportamento da criança.

Em se tratando especificamente de narrativas em livros ilustrados, Nikolaveja (2013) defende que a leitura desses livros prepara as crianças para lidar com a empatia na vida real, pois mesmo crianças muito jovens entendem e respondem à dimensão emocional em livros ilustrados. De acordo com a autora, embora os livros infantis ilustrados tenham sido frequentemente usados para apoiar as habilidades de leitura das crianças pequenas, e ainda que, paulatinamente, sejam reconhecidos como importantes instrumentos para a alfabetização visual, eles têm sido amplamente negligenciados como um caminho no desenvolvimento 
emocional das crianças. Entretanto, as conquistas recentes na pesquisa em cognição, oferecem aos estudiosos da literatura infantil, especialmente estudiosos de livros ilustrados, novas maneiras de olhar esses livros, que podem informar os professores sobre a alfabetização emocional das crianças.

Entre essas novas formas de olhar, conforme a autora, está justamente a empatia, isto é, a capacidade de compreender as emoções de outras pessoas, que é a capacidade mais importante que distingue os seres humanos de outros organismos vivos e uma das habilidades sociais mais essenciais. Porém, essa capacidade não aparece automaticamente; normalmente surge aos 4 anos e se desenvolve gradualmente em direção à adolescência e, para a autora, como todas as outras literacias, essa pode ser aprimorada e desenvolvida.

Para Nikolaveja (2013), uma maneira potencial de promover a empatia em crianças pequenas é por meio de livros ilustrados. Como toda ficção, os livros ilustrados representam as emoções dos personagens, assim como sua interpretação das emoções do outro. No entanto, os livros ilustrados possuem o diferencial de evocar o nosso envolvimento emocional tanto por meio de imagens como de palavras e, além disso, por meio da amplificação de palavras por imagens. Muitos livros ilustrados podem transmitir emoções fortes para as quais as palavras seriam insuficientes e inadequadas.

Esse conhecimento, ainda segundo a autora, é benéfico e necessário, porque as crianças pequenas têm uma experiência limitada de vida com emoções, de modo que os livros ilustrados oferecem uma experiência emocional vicária da qual as crianças podem participar, uma vez que a ficção cria situações em que as emoções são simuladas. Dessa forma, a leitura de ficção prepara as crianças para lidar com a empatia na vida real, contribuindo para aumentar as habilidades cognitivas, emocionais e sociais, sendo importante recurso no exercício de se tornar um membro empático na sociedade. Uma vez que tendemos a ler ficção porque queremos aprender mais sobre nós mesmos e as outras pessoas, os livros ilustrados são um importante meio para essa aprendizagem.

Nikolaveja (2013) destaca que existe um amplo espectro de emoções que imagens, sozinhas ou em combinação com palavras, podem retratar, auxiliando no desenvolvimento das habilidades de empatia, que tipicamente começa com o reconhecimento de emoções primárias, como alegria, tristeza, medo e raiva. Não por acaso, um vasto número de livros ilustrados concentra-se nessas emoções, que são universais e independentes da linguagem verbal. Conforme a autora, a manifestação física das emoções básicas, principalmente a expressão facial, mas também a postura corporal e os gestos, normalmente não requerem nenhum treinamento especial, de modo que as crianças pequenas podem não saber exatamente o que significam frases verbais como "Ele estava triste" ou "Ela estava assustada", mas elas responderão à representação visual de tristeza ou medo. Para ela, há um amplo espectro de emoções que as imagens, sozinhas ou em combinação com palavras, podem retratar.

De acordo com Nikolaveja (2013), a resposta emocional a imagens emocionais é possível porque as memórias da emoção são armazenadas a partir da experiência da vida real ou de uma experiência anterior com a ficção, seja verbal, visual ou multimídia. Assim, ainda que não se tenha uma experiência direta de uma emoção extrema, a pouca experiência é suficiente para acionar a memória. Nesse sentido, na leitura de imagens, o leitor procura sinais externos de emoções, como o faz na vida real.

Com base na pesquisa em cognição, a autora afirma que as características mais proeminentes que refletem as emoções humanas são os olhos e a boca, e essas características são universais, o que justifica o fato de os emoticons funcionarem como uma comunicação visual universal. $\mathrm{O}$ formato da boca é, para ela, o traço mais saliente e, portanto, é muito usado em livros ilustrados: felicidade e tristeza são claramente reconhecíveis pelos cantos da boca virados para cima e para baixo; uma boca bem aberta pode significar medo ou raiva; olhos bem abertos podem sinalizar surpresa ou medo; uma combinação de olhos fechados e 
boca aberta sugere sofrimento; sobrancelhas levantadas podem transmitir raiva. Porém, conforme sublinha, a expressão facial não é a única maneira de comunicar emoções, uma vez que, como demonstra a ciência cognitiva atual, as emoções são incorporadas, isto é, ligadas aos movimentos do corpo, como descreve Damásio (2012 [1994]), e à posição espacial. Isso permite reconhecer emoções, tanto na vida real quanto nas representações visuais, por meio da projeção de nossas próprias emoções.

Nos livros infantis ilustrados, esse reconhecimento dá-se não apenas com personagens humanos, como também com personagens não humanos, como animais, brinquedos e objetos. Como destaca Nikolaveja (2013), somos capazes de nos envolver com as emoções de tais personagens porque as "antropomorfizamos", atribuindo-lhes consciência humana. Por isso, é possível ter empatia por personagens que na vida real podem ser considerados repugnantes, como sapos, lagartas e camundongos, ou perigosos, como ursos e leões.

Além desses conhecimentos, há, ainda, os conhecimentos sobre convenções artísticas e sobre representações gráficas. Ao ler imagens de livros ilustrados, leem-se personagens em primeiro plano e posicionados no centro ou no alto da página como felizes e contentes, e personagens posicionados nos cantos ou para o fundo como infelizes, solitários e assustados. Também associam-se cores a humores, como o vermelho com agressão e cinza e preto com angústia. Afora isso, linhas de movimento podem significar emoções fortes, como medo e raiva, balões de pensamento podem conter outras imagens refletindo o estado de espírito do personagem, emoticons podem ampliar o espectro de emoções em narrativas multimídia, como uma boca em zigue-zague significando raiva ou medo. Nikolaveja (2013) destaca que a compreensão de tais convenções é uma questão de alfabetização visual e, portanto, pode ser encorajada e exercitada.

Contudo, na maioria dos livros ilustrados, as imagens são complementadas por declarações verbais (NIKOLAVEJA, 2013). A maneira mais primitiva de expressar uma emoção em um texto literário é afirmar que alguém está feliz, triste ou com raiva, o que pode ser expresso por meio de um narrador ou pelo discurso ou pensamento direto de uma personagem. Nos dois casos, as palavras acionam as memórias associadas às respectivas emoções, o que permite a leitura da mente de uma personagem (NIKOLAVEJA, 2012). Para Nikolaveja (2013), as imagens e as declarações verbais podem ser mutuamente complementares, reforçadoras ou contraditórias. As declarações verbais são mais precisas e concretas que as imagens, mas também mais restritivas. As emoções são, por definição, nãoverbais, por isso os livros ilustrados oferecem uma oportunidade única de se envolver com a empatia, contornando os limites da linguagem verbal. Segundo a autora, os livros inteligentes utilizam a ambiguidade para transmitir o estado emocional de uma personagem. Por meio de uma imagem, é provável que o leitor escolha uma das emoções básicas, enquanto nuances da emoção podem ser expressas verbalmente, como a melancolia e a ansiedade. As crianças não têm dificuldade em responder adequadamente às imagens sem o suporte das palavras, de maneira que a descrição verbal de emoções e humores pode ser usada como um dispositivo pedagógico que ajuda crianças pequenas a articular a emoção para reconhecê-la mais tarde, mas talvez também como um passo na aquisição da linguagem: do básico "triste" para uma ampla gama de emoções.

Quanto às emoções secundárias, sociais ou cognitivas superiores, como amor, culpa, vergonha, orgulho, inveja e ciúme, Nikolaveja (2013) afirma que, não sendo inatas, mas culturalmente dependentes, elas estão sujeitas a negociações entre as pessoas. Por exemplo, o amor é uma emoção social que exige que os objetivos finais de dois indivíduos, para serem felizes, se tornem igualmente valiosos para ambos. A maioria dos livros ilustrados envolve pelo menos duas personagens e, desse modo, tende a explorar emoções mais complexas, não apenas na descrição de conflitos entre os personagens, mas também no retrato de personagens desenvolvendo empatia em relação a outras. Com isso, há várias possibilidades de 
identificação com personagens, oferecendo possibilidades de mais de uma perspectiva emocional, até mesmo em livros consideravelmente menos sofisticados.

Nikolaveja (2013) conclui que a leitura nos torna seres humanos melhores, e as imagens visuais são meios importantes para o desenvolvimento da empatia. Isso potencialmente tem amplas implicações para os profissionais, porque, com esse entendimento, a importância dos livros ilustrados vai muito além de ser uma questão de leitura para leitores emergentes. Para a autora, a crença comum de que os livros ilustrados são destinados a crianças muito pequenas, de que a alfabetização escolar deve envolver principalmente o domínio da linguagem verbal e escrita e de que existe uma supremacia do verbal sobre o visual, típica da educação ocidental formal, lamentavelmente resulta em crianças perdendo sua habilidade inata de se envolver com imagens, que está diretamente relacionada à sua afetividade. Afora isso, os livros ilustrados aumentam a apreciação estética dos jovens leitores, e as narrativas de ficção ilustradas são, em síntese, sobre comunicação interpessoal, permitindo aprender mais não apenas sobre nós mesmos, como também sobre outras pessoas, de modo que os livros ilustrados são um excelente primeiro passo em direção à inteligência emocional. Por essa razão, proponho a análise a seguir.

\section{Leitura de emoções e empatia em um livro infantil ilustrado}

Nesta análise, tenho por objetivo demonstrar nossa proposta de leitura de emoções circunscritas em um livro infantil ilustrado, a partir dos fundamentos das pesquisas supracitadas. O livro foi escolhido pelo critério de acessibilidade, por pertencer ao acervo pessoal da pesquisadora. Também foram levados em consideração estes critérios: (i) ser uma obra de produção nacional (não traduzida) uma vez que a análise de uma tradução exige outros fundamentos teóricos que ultrapassam os objetivos deste trabalho; (ii) ser voltada para o público-alvo em estudo, isto é, o leitor iniciante (seis a oito anos); e (iii) ter imagens disponibilizadas na web, respeitando-se os direitos autorais, mas também permitindo uma melhor contextualização para o leitor deste artigo. Além desses, considerando o objetivo proposto, foi adotado como critério essencial para este estudo a seleção de uma obra cuja temática não versasse diretamente sobre emoções. Ora, se o propósito é oferecer uma perspectiva sobre a leitura de emoções presentes em livros infantis ilustrados, a seleção de uma obra voltada para a temática das emoções poderia direcionar, equivocadamente, a percepção de que existe um tipo específico de narrativas para a abordagem da leitura de emoções, o que é o oposto do que foi argumentado até aqui. Proponho, portanto, a consideração de um aspecto da leitura de narrativas pouco explorado no ensino, que é o da leitura das emoções de personagens de ficção motivada pelo desejo de entender melhor a si mesmo e ao outro, e, ao mesmo tempo, favorável ao desenvolvimento da empatia na criança.

A análise, pautada nos princípios da Análise de Conteúdo, conforme descrita por Bardin (1977), orienta-se pelas categorias da relação texto-imagem, conforme Nikolaveja (2013), quais sejam, relação de complementação, de reforço ou de contradição. As unidades de análise foram definidas por sequências completas de sentido, em que texto e imagem constroem uma cena da narrativa. Essas cenas são construídas quer em páginas simples, quer em páginas duplas. Em cada cena são examinadas, a partir dos índices destacados por Nikolaveja (2013), as palavras e/ou ilustrações relacionadas às personagens, que possam fazer referência, em um primeiro momento, a emoções primárias, mas analisam-se, também, índices verbais e visuais que, a partir das emoções básicas, possam assinalar nuances de emoções sociais mais complexas. Identificadas essas palavras e/ou imagens, analisam-se a relação entre elas e discutem-se, por inferência, possibilidades de leitura de emoções de si e do outro. 
A amostra consiste na obra Quem soltou o pum?, escrita por Blandina Franco e ilustrada por José Carlos Lollo, e lançada em setembro de 2010, pela Companhia das Letras. O livro contém 32 páginas, nas quais 14 cenas são configuradas em páginas duplas. Na página da editora e na FlipPage, são disponibilizadas imagens de 04 imagens, que serão reproduzidas aqui. As imagens não disponibilizadas serão descritas textualmente durante a análise.

Figura 1 - Capa

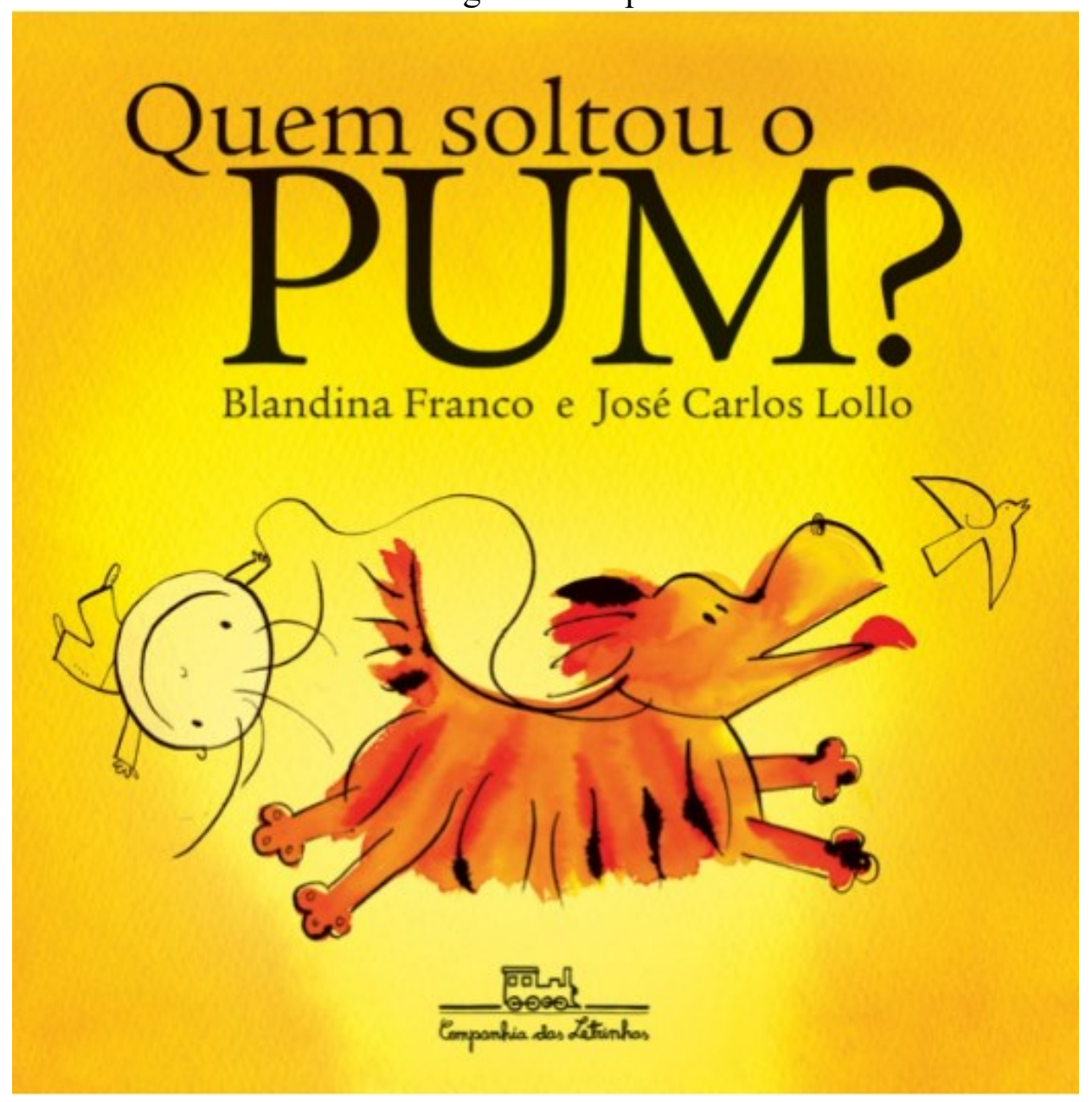

Fonte:

\section{Companhia das Letras.}

Na página da editora, a obra é apresentada como uma história simples, mas com uma "sacada" das boas:

Imagine um cachorrinho de estimação que se chama Pum! Daí dá para tirar diversos trocadilhos, criando frases e situações realmente hilárias. É um tal de não conseguir segurar o Pum, que é barulhento e atrapalha os adultos, que dizem que o Pum molhado, em dia de chuva, fica mais fedido ainda, o que faz o menino passar muita vergonha. Pobre Pum. E pobre dono do Pum! Mas não tem jeito, com o Pum é assim mesmo: simplesmente ninguém consegue evitar que ele escape e cause certos inconvenientes. (COMPANHIA DAS LETRAS)

Há, ainda, um chamamento antecedente à apresentação, que diz: 
Volume 14 - Número 2 - ago/dez de 2019

Um pum pode ser problemático na vida de uma pessoa. Quando ele é um cachorro, então, aí é que ninguém segura. Vira e mexe o Pum escapa, faz barulho e atrapalha os adultos! Um livro divertido e inusitado, de arrancar várias risadas tanto dos filhos quanto dos pais. (COMPANHIA DAS LETRAS)

Como podemos observar, a abordagem principal da obra é o humor, a brincadeira com uma situação constrangedora - "soltar pum", a partir de um jogo linguístico, em que o Pum é, ao mesmo tempo, uma personagem, o cão de estimação. Em que pese a proposta original, podemos observar outras possibilidades de leitura, considerando as diferentes emoções que são experimentadas pelo protagonista, a criança, e pelas demais personagens.

$\mathrm{Na}$ primeira cena, há apenas a voz do narrador protagonista apresentando a personagem Pum como seu melhor amigo. Nessa parte, não há índices evidentes de emoções, mas sim a neutralidade típica de uma exposição inicial que situa o leitor antes do desenvolvimento do conflito. A pata da personagem cobre a boca, mas também cria um efeito de linha reta, que habitualmente é empregada para representar emoções indefinidas:

Figura 2 - Primeira cena

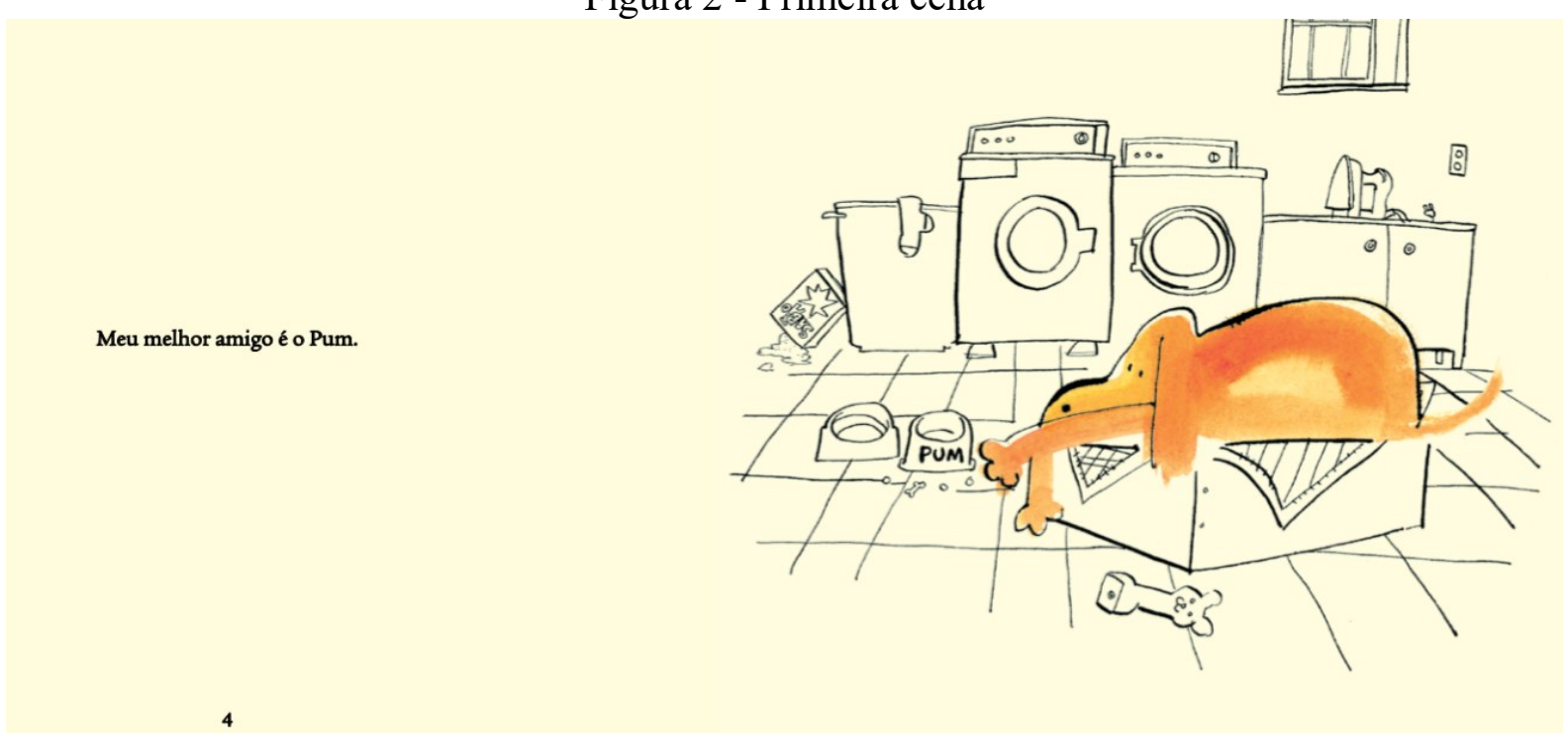

Fonte: Companhia das Letras.

$\mathrm{Na}$ segunda cena, de maneira estratégica, escritor e ilustrador, além de introduzir, progressivamente, o menino protagonista para o leitor, põem em evidência uma emoção primária, a alegria, mediante a centralização da imagem das personagens e o uso de índices emocionais, que são reforçados pelo texto. Na imagem, o protagonista entra na lavanderia, com um sorriso revelado parcialmente, enquanto a personagem Pum apresenta boca ligeiramente inclinada para cima, língua para fora, orelhas e rabo levantados, bem como posição corporal em pé, como se tivesse levantado alegre ao ver o menino chegar. Essas imagens são reforçadas pelo texto "nada me deixa mais feliz do que soltar o Pum", representando a alegria do menino como a possibilidade de realização de um desejo. Desse modo, a narrativa evolui de uma representação emocional mais neutra, para uma representação emocional positiva. 
Volume 14 - Número 2 - ago/dez de 2019

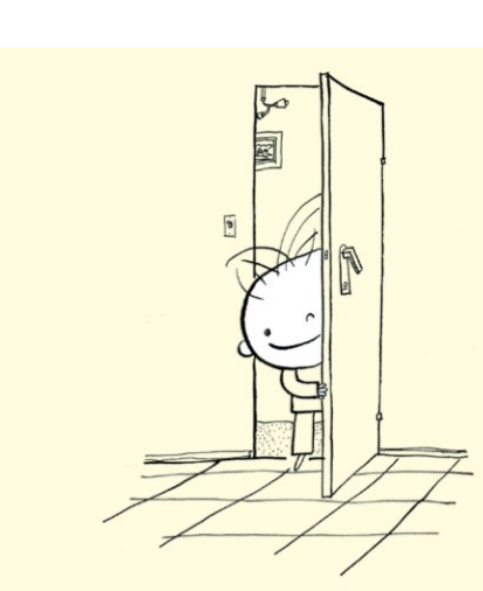

Nada me deixa mais feliz do que soltar o Pum.
Figura 3 - Segunda cena

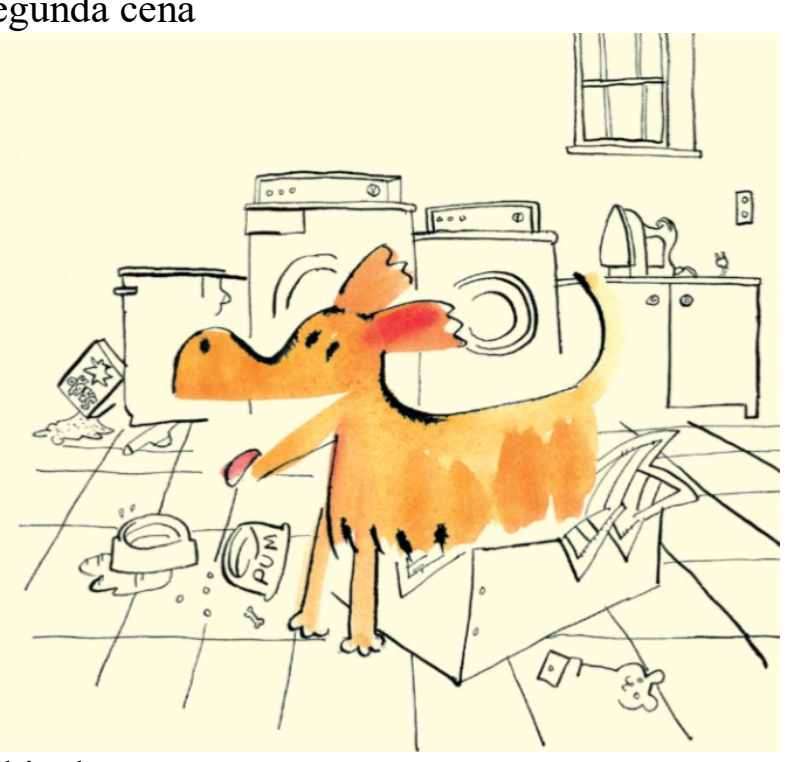

Fonte: Companhia das Letras.

Contudo, após essas cenas, inicia a complicação, em que a estrutura narrativa evolui, passando a ser construída a partir de emoções mais complexas que intensificam o conflito, emoções geradas pela forte oposição à ação do protagonista em ceder ao desejo de soltar o Pum. Desta vez, há uma complexificação na expressão de diferentes emoções, e escritor e ilustrador exploram as emoções complexas, valendo-se, ao mesmo tempo, das relações de reforço e complementação. Nessa cena, a imagem ilustra adultos com expressões variadas, explorando diferentes nuances de emoções, a partir dos elementos chave sobrancelhas e boca. Essas nuances alternam-se do bravo, por meio de sobrancelhas e lábios pressionados, até o susto e o medo, com a boca aberta ou com os cantos virados para baixo. Já o protagonista é retratado com postura cabisbaixa, com os cantos da boca virados para baixo, indicando tristeza ou, ainda, vergonha. Em sua relação com o texto, encontramos índices de reforço, como "as pessoas olham feio para mim" e de complementaridade, como em "eu acabo levando um monte de bronca à toa", descrição que não é retratada na imagem.

Nas cenas subsequentes, o protagonista prossegue narrando eventos semelhantes, nos quais os adultos estão reiteradamente bravos com o fato de o menino soltar o Pum, e o protagonista é retratado com a emoção de tristeza por conta dessa reação emocional dos adultos. Essas cenas são intercaladas com outras em que a emoção retratada é a alegria, que correspondem aos momentos em que o protagonista está apenas com seu cão, sem a presença de adultos. Nas cenas em que as personagens estão bravas, podemos destacar estes exemplos de índices visuais de emoções das personagens: sobrancelhas inclinadas, boca curvada para baixo, dedo para o alto e braços apoiados na cintura, no caso das personagens adultas, e postura predominantemente cabisbaixa da protagonista. Esses índices visuais continuam sendo construídos em relações de reforço ou de complementaridade com os índices verbais, tais como: "levei a maior bronca da síndica", "minha mãe ficou brava de verdade", "um dia um vizinho acabou reclamando com meu pai", "por que será que as pessoas ficam bravas quando eu solto o Pum e ele faz barulho?" e "minha mãe ficou brava de novo". 
Volume 14 - Número 2 - ago/dez de 2019

Figura 4 - Parte da quarta cena (FlipPage)

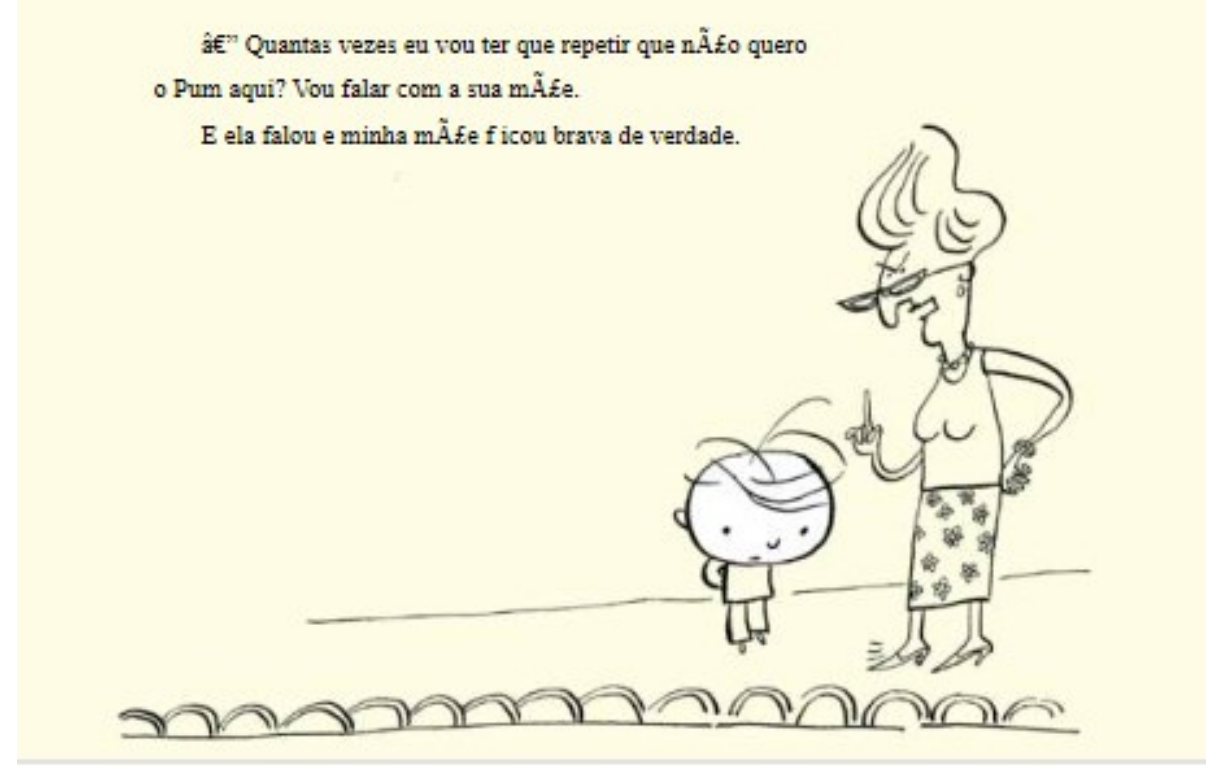

Fonte: Companhia das Letras.

Essas relações são utilizadas no desenvolvimento do conflito, até que os autores ampliam as estratégias de construção da relação palavra e imagem, introduzindo o contraponto, em que a ilustração contradiz parcialmente o texto. Esse recurso confere mais profundidade à narrativa, correspondendo, não por acaso, ao clímax do enredo. A cena é complexa, pois há diferentes personagens e, por conseguinte, diferentes emoções representadas. O protagonista conta que no Natal passado o Pum escapou e "emporcalhou" a calça da tia Clotilde. Por isso, o pai do menino pergunta quem soltou o Pum, e o menino responde que foi o irmão menor, por estar cansado de passar vergonha e levar a culpa. Nessa cena, encontramos as relações de reforço, com a imagem do pai bravo, e de reforço e complementaridade relativamente ao protagonista, que é retratado sem traços que denotem emoção, com a boca em linha reta e com o dedo apontando para a imagem de um bebê, igualmente sem expressão. O contraponto é evidenciado na construção das emoções da personagem tia Clotilde, pois, embora a construção da cena oriente para a desaprovação dos adultos, essa personagem não é retratada como brava ou descontente por ter suas calças "emporcalhadas"; antes, pelo contrário, é ilustrada com uma grande boca em forma de riso, deixando mais abertas, para o leitor, as possibilidades de leitura das emoções.

Após o clímax, a narrativa encaminha-se para o desfecho, voltando a evidenciar a emoção básica da alegria, ainda com uma cena com a personagem tia Clotilde, e todas as demais apenas com o protagonista e o Pum. Os índices verbais e visuais são semelhantes aos anteriores, e as relações são de reforço e de complementaridade. Na cena final, a emoção que se destaca é, novamente, a da alegria, mas, diferentemente da exposição inicial do enredo, o desfecho é construído pelas relações de complementaridade e oposição. Palavra e imagem não coincidem, mas se complementam e se contradizem. O protagonista é retratado com um grande sorriso, sendo puxado, em posição inclinada pelo Pum, como na imagem de capa, ampliando a representação da alegria. Não há índices verbais que representem diretamente emoções. Por inferência, a partir de índices como "eu acho todas essas broncas por causa do Pum uma grande injustiça" e "não é culpa minha", podemos considerar que os autores 
resgatam o conflito, apresentando como solução a autoaceitação da criança, que gera a alegria.

Como observamos, autor e ilustrador não apenas constroem possibilidades de leitura a partir das emoções, como o fazem de maneira criativa e estratégica. Iniciam com a estratégia mais comum de construção da relação texto e imagem, que é a de reforço, para explorar a emoção primária da alegria, experimentada antes do conflito. Conforme evolui a narrativa, vão incrementando habilmente essa relação com a de complementaridade, até alcançar a de contradição, que coincide com o clímax e promove a amplificação de emoções sociais mais complexas, isto é, da tristeza à culpa e vergonha. Com o desfecho, apresentam a solução para o conflito, que é o retorno da emoção básica da alegria, mas, agora, após o conflito, a despeito da reclamação das demais personagens, com relações de complementaridade e contradição que podem ampliar o espectro de leitura da criança sobre as emoções positivas. Dessa forma, podemos evidenciar como a criação de narrativas ficcionais ilustradas pode explorar uma gama de possibilidade de leitura de emoções, a partir de palavras e imagens, o que pode favorecer tanto a alfabetização verbal e visual, como a emocional.

Do ponto de vista do leitor, ainda que cada leitura será individual, conforme as experiências prévias (MIALL, 1989), é bastante evidente que há, na obra, representações de emoções com as quais as crianças podem se identificar. As crianças podem sentir empatia pela protagonista e se identificar com seus sentimentos diante da reprovação dos adultos, especialmente dos pais. A criança pode compreender que é natural sentir-se triste com essa reprovação, e ampliar essa compreensão para o entendimento de quando sente culpa ou vergonha. Também pode compreender que, a despeito disso, pode voltar a sentir alegria, por meio da autoaceitação. Quanto à empatia, além de aprender mais sobre si, outras possibilidades de leitura emocional podem ser realizadas na busca de compreender as emoções dos outros. Uma leitura possível, é a de que nem sempre a realização do desejo do eu recebe a aprovação do outro. Além dessa, a criança também pode ler que determinados comportamentos despertam emoções nos outros. Como a cognição é corporificada, a criança tem, ainda, a oportunidade de compreender linguagens corpóreas, que também comunicam as emoções humanas e, a partir das relações de contradição, entender que, às vezes, essas linguagens são uma boa fonte de informação sobre as emoções de outrem, muitas vezes opondo-se ao que é dito verbalmente.

Uma observação, entretanto, é necessária. A obra retrata pais e adultos, à exceção da tia, apenas como figuras bravas, sem índices verbais ou visuais de emoções mais positivas, como o amor. Isso é um alerta para a importância de conhecer como as crianças estão lendo os livros e de compreender a leitura emocional que as crianças fazem. Antes de ser um problema (e não o é, porque um dos papéis da literatura consiste em retratar mundos possíveis), pode ser uma oportunidade de diálogo proporcionada pelas obras, permitindo conhecer melhor a criança. Nesse sentido, para além do potencial de desenvolvimento das emoções na infância, anunciado por Nikolaveja (2013), as narrativas ilustradas podem ter o benefício adicional de melhorar a compreensão entre o adulto e a criança, favorecendo a empatia entre ambos.

\section{Conclusão}

Este trabalho teve por objetivo propor um olhar para o livro infantil ilustrado que valorize a experiência vicária da criança na interação com as emoções das personagens, ressaltando o papel dessa experiência no desenvolvimento da empatia. Para isso, realizamos a análise de uma narrativa infantil ilustrada, demonstrando como esta pode explorar uma gama de possibilidades de leitura de emoções, a partir das diferentes relações entre palavras e imagens. A partir da análise, discutimos como essas possibilidades de leitura podem 
favorecer, além da alfabetização verbal e visual, a alfabetização emocional, o que pode melhorar a compreensão da criança acerca de suas emoções e de emoções alheias, favorecendo a empatia.

Evidentemente, outras possibilidades de leitura de emoções podem ser realizadas, uma vez que isso dependerá dos objetivos e experiências prévias de cada leitor. Ainda assim, o objetivo de lançar luz sobre esse aspecto parece ser essencial para a formação do leitor, conforme demonstra a pesquisa em cognição. Pela análise realizada, parece bastante evidente que há a necessidade de oportunizar à criança a escolha de obras de seu interesse, que satisfaçam suas necessidades emocionais. Além disso, é igualmente relevante dialogar com ela a respeito de sua leitura das emoções das personagens.

Importa ressaltar que nossa proposta não tem por intenção substituir as abordagens da leitura que exploram as estratégias cognitivas, e sim revelar como a dimensão emocional é igualmente necessária para a formação do leitor. As ciências cognitivas trazem evidências não apenas sobre o uso da memória ou da atenção na leitura, mas também sobre o papel das emoções na compreensão leitora, que permite, de forma vicária, uma melhor compreensão de si e do outro, favorecendo a empatia. Esse entendimento permitirá uma abordagem da leitura mais integrada, que respeite a criança em todas as suas dimensões, cognitiva, emocional e cultural, valorizando, principalmente, sua singularidade.

\section{Referências}

ASSIS BRASIL, L. A. Escrever ficção. Um manual de criação literária. São Paulo: Companhia das Letras, 2019.

BARDIN. L. Análise de conteúdo. Lisboa: Editora Edições 70, 1977.

COMPANHIA DAS LETRAS. Apresentação. Companhia das letrinhas. Quem soltou o Pum? Disponível em: https://www.companhiadasletras.com.br/detalhe.php?codigo=40638. Acesso em: 30 out 2019.

DAMÁSIO, A. O erro de Descartes: emoção, razão e o cérebro humano. 3. ed. São Paulo: Companhia das Letras, 2012.

DÁVALOS, M. T.; LEÓN, J. A. Inferencias emocionales en los procesos de comprensión del discurso. In: MIRAMONTES, Z.; GARCÍA, R. Comprensión y aprendizaje a través del discurso. Madri: LEED, 2017.

DIJKIC, M.; OATLEY, K. MIHNEA, C. Reading Other Minds: Effects of Literature on Empathy, University of Toronto, 2013.

MARMOLEJO-RAMOS, F.; HEREDIA, A. Inferencias, modelos de situación y emociones en textos narrativos. El caso de los niños de edad preescolar. Revista Intercontinental de Psicología y Educación, México, n. 8, p. 94-138, jul-dez. 2006. Disponível em: $<$ http://www.redalyc.org/articulo.oa?id=80280207>. Acesso em: 30 out. 2019.

MIALL, D. Beyond the Schema Given: Affective Comprehension of Literary Narratives, v. 1, n. $3, \quad$ p. $55-78, \quad 1989 . \quad$ Disponível em: $<$ https://sites.ualberta.ca/ dmiall/reading/Beyond_s.htm>. Acesso em: 30 out. 2019.

NIKOLAJEVA, M. Reading other people's minds through word and image. Children's Literature in Education, v. 43, n. 3, p. 273-291, 2012. Disponível em https://link.springer.com/article/10.1007\%2Fs10583-012-9163-6. Acesso em: 16 jan. 2020.

NIKOLAVEJA, M. Picturebooks and emotional literacy. The Reading Teacher, v. 67, n. 4, 2013. DOI:10.1002/TRTR.1229, p. 249-254. 